\section{Questión}

Periodismo / Comunicación ISSN 1669-6581
- Av. $44 \mathrm{~N}^{\circ} 676,1^{\circ}$ piso

CP 1900 - La Plata - Argentina

www.perio.unlp.edu.ar/question

Por el derecho a una muerte digna

Gabriela Naso

https://doi.org/10.24215/16696581e369

\title{
Por el derecho a una muerte digna
}

\section{For the right to a dignified death}

Periodista especializada en derechos humanos. Licenciada en Periodismo por la Universidad Nacional de Lomas de Zamora y maestranda en Periodismo Documental por la Universidad Nacional de Tres de Febrero. gaby.m.naso@gmail.com www.gabrielanaso.com.ar

\section{Palabras clave}

Identificación - Dignidad - Mala muerte - Rituales

\section{Keywords}

Identification - Dignity - Bad Death - Rituals

La despersonalización de la muerte es una de las caras de la pandemia. ¿Cuál es el destino de los cadáveres? ¿Es posible garantizar un manejo seguro y respetuoso? ¿Cómo se procesan las pérdidas ante la falta de cuerpo? Mientras los fallecidos se cuentan de a miles, se habla de ellos con una opacidad difícil de atravesar. 


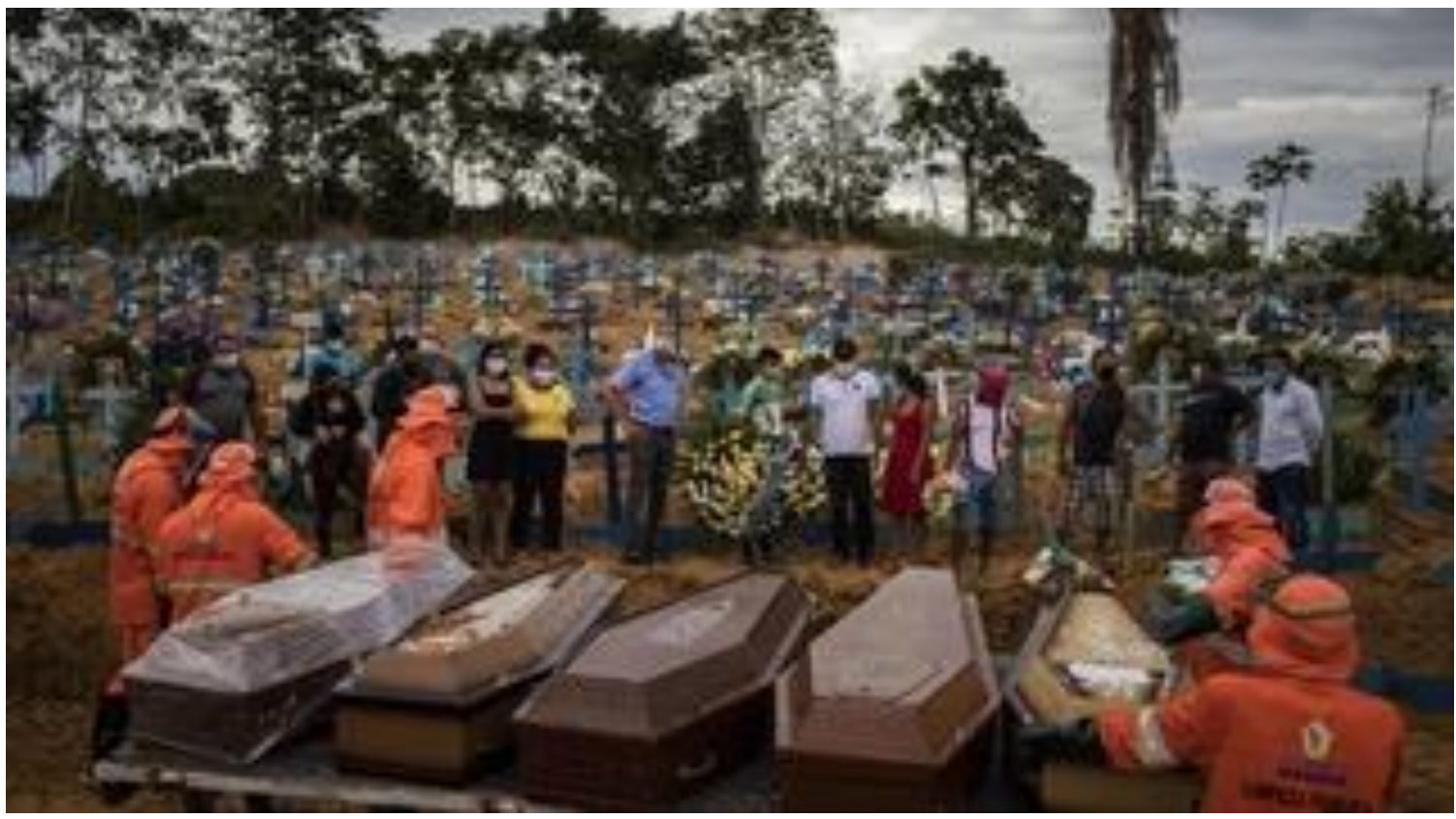

La temprana oscuridad del invierno italiano cubre el centro de Bérgamo, mientras una treintena de camiones militares cruzan las calles desiertas. Avanzan en fila hacia las afueras. El cortejo transporta cerca de 60 féretros de víctimas de coronavirus para su incineración en otras ciudades, tras el colapso del cementerio local.

En España, el desborde de las morgues convierte a los palacios de hielo de Madrid y Majadahonda en depósitos de cadáveres infectados. También en Ecuador los sitios para albergar restos humanos ven sobrepasada su capacidad. Los cuerpos se amontonan en las casas, las calles y las morgues de Guayaquil, donde cientos de familias deben esperar más de dos semanas para enterrar a sus seres queridos.

Al noroeste de Nueva York, la Isla de Hart es el escenario por el que desfila la maquinaria pesada: grandes palas excavadoras que abren zanjones en las entrañas de ese trozo de tierra estadounidense, donde se apilan los ataúdes. La práctica se repite en los recónditos rincones de la selva amazónica. Azotada por la crisis sanitaria, Manaos, la capital del estado norteño de Brasil, realiza entierros masivos en fosas comunes.

También Colombia tiene una cicatriz que la distingue: las camas hospitalarias de cartón que se convierten en féretros son parte de la pesadilla. 
Las imágenes de este mal sueño demasiado real dan vuelta al mundo y, a su paso, despiertan el miedo. Pero, de algún modo, es como si todo eso transcurriera en secreto. Los fallecidos se cuentan de a miles, pero no se habla de su destino ni de sus derechos. Un consternado silencio rodea la muerte, mientras la pandemia modifica los ritos que la envuelven. Es como si nadie quisiera enterarse, como si la incertidumbre y el terror consumieran el corazón de los vivos.

Consultado por "Question", el director ejecutivo del Equipo Argentino de Antropología Forense (EAAF), Luis Fondebrider, afirma que se trata de un "tema tabú": "Todos los países tienen comités de científicos y médicos, pero ninguno habla de qué se hace con los cadáveres". La falta de información y la poca claridad en las acciones alimentan el mito de que "la muerte siempre está oculta" y crean dudas "en los familiares y la población".

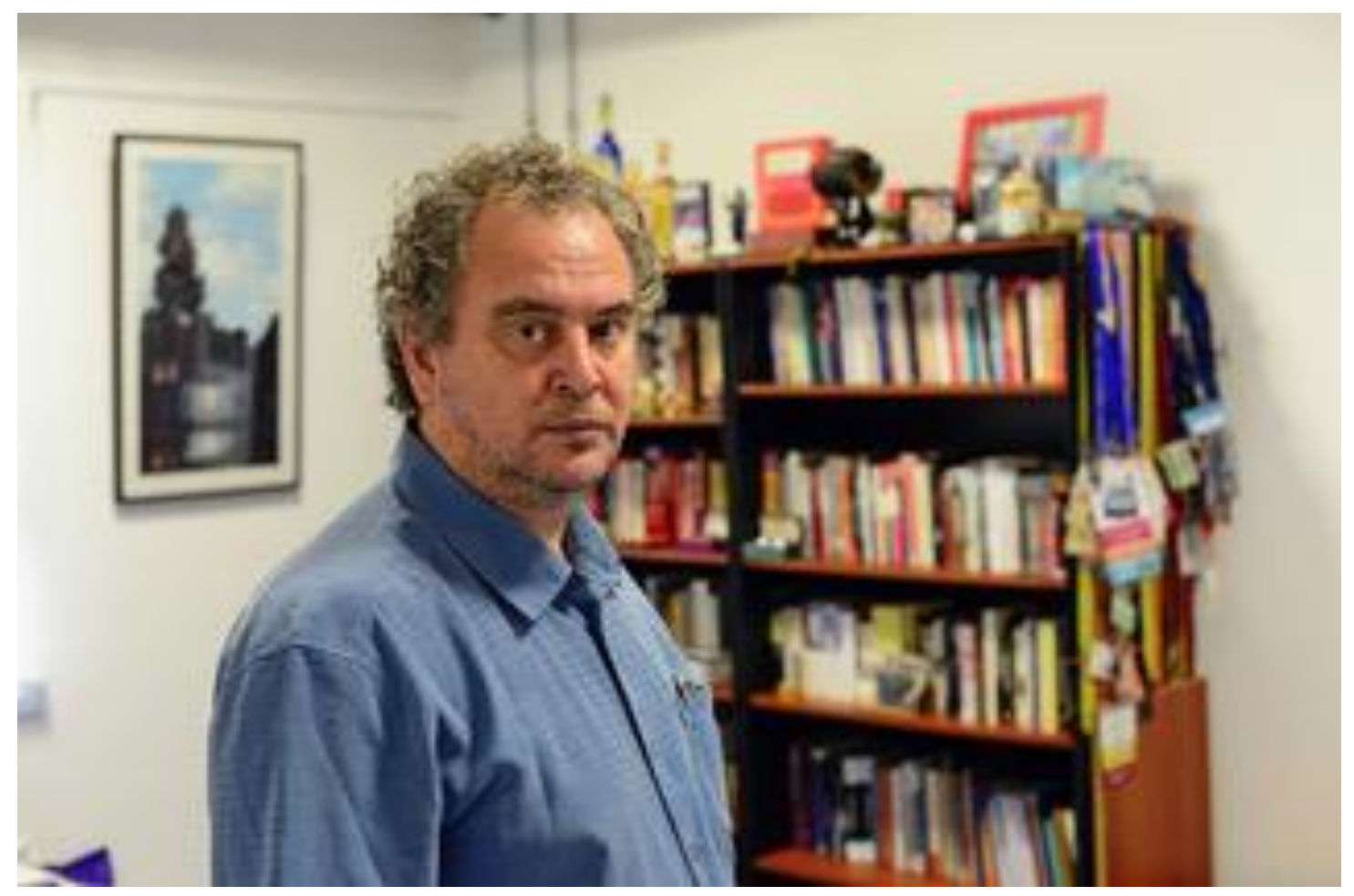

\section{Identificación}

La muerte nos invade y no hay forma de alejarla. Sus cifras son una amenaza: 321 mil personas murieron por coronavirus, según datos oficiales. Con más de 380 fallecidos por la pandemia, 
Argentina está lejos de los países que encabezan el número de víctimas, como Brasil (17.375), España (27.709), Italia (32.169), Francia (28.239), Inglaterra (34.796) y Estados Unidos (92.478). Aunque los números de nuestro país son bajos, Fondebrider advirtió que "el secreto en todo esto es estar preparado" para cuando las necesidades intenten superar los recursos y manifestó su preocupación por el caso argentino: "Siempre hubo, por acción u omisión, problemas sobre dónde están los cadáveres, la notificación a los familiares y la determinación de la causa de muerte. No tenemos una historia impecable de manejo y gestión de cadáveres en el país".

Creado en 1984 para dar respuesta a las miles de familiares que luego de la última dictadura cívico militar querían saber qué había pasado con sus seres queridos, el equipo liderado por Fondebrider se consolidó como un referente mundial.

Según el director y miembro fundador del EAAF, la salida de un cuerpo con la documentación adecuada de un hospital o clínica privada, su llegada a un cementerio y su enterramiento en una sepultura individual señalizada son los momentos más sensibles en la gestión de cadáveres, pues de ellos depende la "trazabilidad del proceso" y la identificación de los cuerpos.

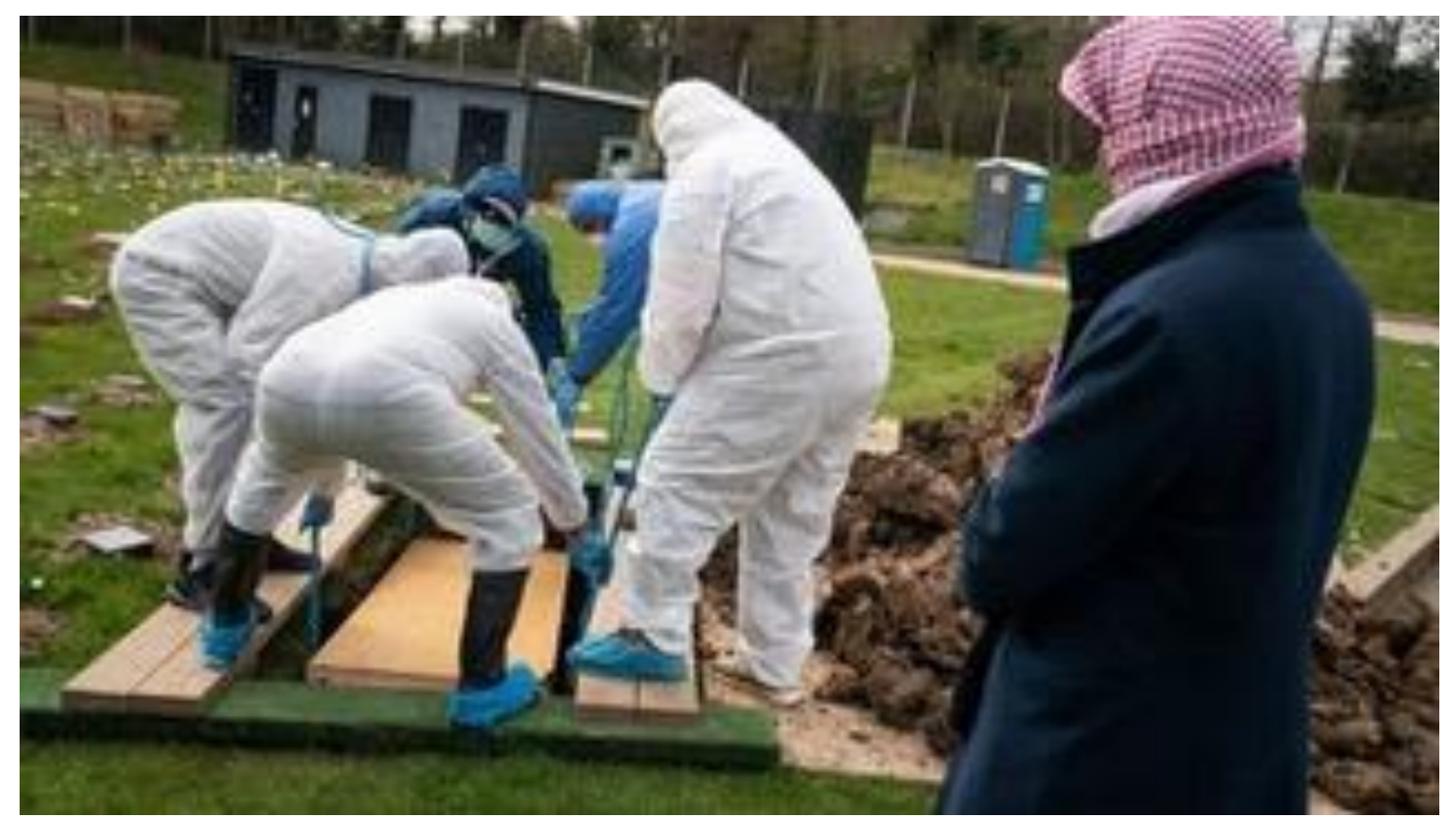




\section{Trato digno y respetuoso}

La pandemia cambió nuestros rituales de la vida y la muerte. Este dantesco universo, regido por el distanciamiento social, nos impuso muertes solitarias, sin rostros familiares ni gestos de amor. ¿Cómo acompañar a una vida que se apaga sin una mano que la sostenga? También las despedidas se volvieron distantes, breves e higiénicas, sin abrazos ni lágrimas presenciales. Aunque no hay evidencia sólida del riesgo de infección a partir de cadáveres de personas fallecidas por COVID-19, la experiencia adquirida frente a otros virus hace suponer que podrían ser un peligro para el personal médico, forense y funerario, y los familiares que entren en contacto directo con ellos.

La falta de certezas multiplica las incógnitas: ¿Dónde se manipulan los restos de una persona que murió por el virus o sospechosa de haber estado infectada? ¿Qué información debe recibir la familia? ¿En qué sitio espera el cadáver hasta la finalización de los trámites administrativos? ¿Cómo garantizar el transporte seguro y respetuoso de los cuerpos hasta su disposición final? En Argentina, hay más de protocolo para contestar estos interrogantes.

Dos días antes de que se decretara el Aislamiento Social, Preventivo y Obligatorio, la Dirección Nacional de Calidad en Servicios de Salud y Regulación Sanitaria, que depende del Ministerio de Salud de la Nación, publicó una guía de pautas para el manejo seguro de cadáveres. Al instructivo elaborado por la cartera de Ginés González García, el cual fue actualizado el 23 de abril, se suman las recomendaciones de Buenos Aires, Santa Fe, Córdoba, La Pampa, Neuquén, Mendoza, Capital Federal, Policía Científica y el Cuerpo Médico Forense.

La proliferación de criterios en cuestiones tan sensibles es riesgosa y, al mismo tiempo, evidencia la falta de consenso entre las partes involucradas en el manejo de los cuerpos. Con la experiencia de haber trabajado en más de 30 países, Fondebrider no deja lugar a dudas: "Hay que sentar a todas las instancias estatales y no estatales que se encargan de la gestión de los cadáveres a una misma mesa y trabajar un protocolo común". En otras palabras: todos los operadores involucrados en el proceso, a nivel nacional, provincial y municipal, deben realizar sus tareas "bajo una misma coordenada", estar equipados con los materiales adecuados y contar con la infraestructura necesaria.

En ese sentido, el antropólogo recomienda aplicar el protocolo del Comité Internacional de la Cruz Roja (CICR), basado en el manual de la Cruz Roja y la Organización Panamericana de la 
Salud (OPS) sobre manejo y gestión de cadáveres en desastres. Varios países se apoyaron en este modelo para redactar sus propios instructivos.

La dispersión y la desinformación es una problemática extendida a escala mundial. Por eso, la Biblioteca del EAAF (https://eaaf.org/covid-biblioteca-forense/) puso a disposición de los estados y sus ciudadanos más 60 documentos en distintos idiomas, de forma libre y gratuita. El repositorio digital reúne pautas de organismos internacionales, como el CICR, la OPS, la Organización de las Naciones Unidas (ONU) y la Organización Mundial de la Salud (OMS), y recomendaciones de más de veinte países. Además, ofrece datos y gráficos actualizados en tiempo real para analizar la evolución de la pandemia en función de las medidas adoptadas por los distintos gobiernos.

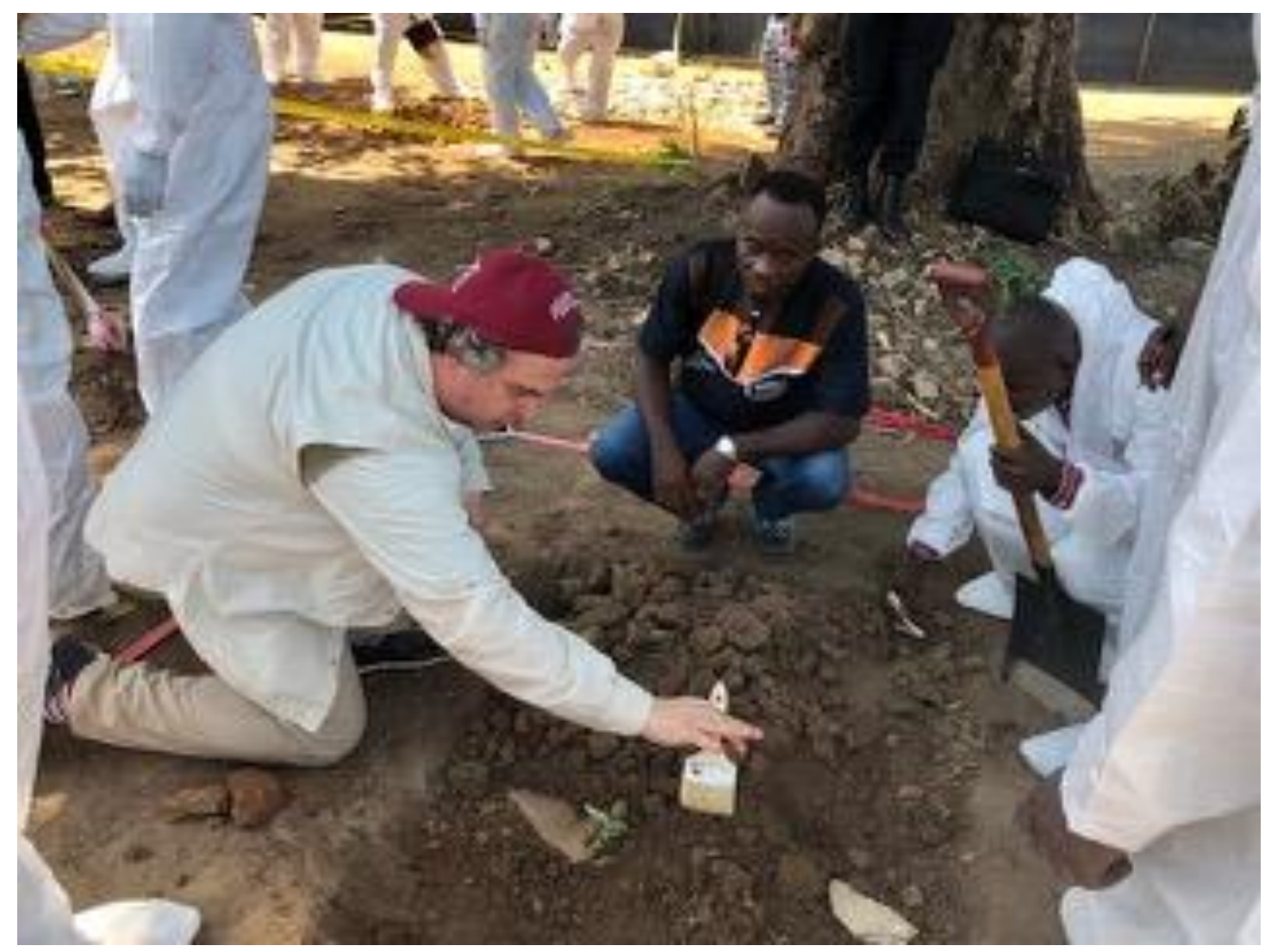




\section{Pautas e interrogantes}

"Se han suspendido los cuidados usuales a los cuerpos, como la conservación por tanatopraxia o los ritos judíos y musulmanes de limpieza y purificación que ayudan al alma a emprender su viaje póstumo. Estas prácticas rituales de limpieza y estética sobre los cuerpos se vieron reemplazadas por otras de limpieza sobre los espacios que intentan evitar la contaminación". La reflexión pertenece a la antropóloga e investigadora Conicet Laura Panizo y a su colega francesa Valérie Robin Azevedo, quienes en el artículo "Reconvertir la 'mala muerte' en época de Covid19", publicado en el marco del programa "Transfunaire - Violencia masiva y prácticas funerarias", ahondan sobre las prácticas relativas a los fallecidos y los moribundos.

En esta transición permanente, las medidas sanitarias y los rituales mortuorios habituales se ven en obstaculizados. Las políticas públicas de salud establecen que los cuerpos tienen que transferirse "lo antes posible al depósito". Previamente, los familiares "más próximos y cercanos" deben tener acceso para despedirse "sin establecer contacto físico con el cadáver, ni con las superficies u otros enseres de su entorno o cualquier otro material".

Luego, los restos deben "introducirse en una bolsa plástica de alta densidad, impermeable y con cierre hermético, debidamente identificada como material infectocontagioso, que reúna las características técnicas sanitarias de resistencia a la presión de los gases en su interior, estanqueidad e impermeabilidad".

En cuanto a la disposición final de los cuerpos, Argentina contempla la conservación, la inhumación, la cremación y el traslado al extranjero, según los ritos religiosos, las costumbres del lugar y/o las resoluciones judiciales.

El virus que arrebata vidas a escala de las grandes pestes puso el foco sobre la poca capacidad de las morgues y la importancia de contar con espacios transitorios refrigerados, que no siempre existen, para depositar los cadáveres hasta su traslado al cementerio.

Hay otras cuestiones a tener en cuenta: aquellas vinculadas a las autopsias. En general, los protocolos recomiendan no practicarlas. Al ser decesos naturales, los fallecimientos por el virus no requerirían de un examen post mortem. Pero éste no puede obviarse en caso de muertes violentas, sospechosas de criminalidad o en sitios de detención. Son casos complejos que "ameritan ser investigados", apuntó Fondebrider y recordó que no se puede inhumar un cuerpo si saber "con certeza la causa de muerte". 
En el caso de Argentina, la situación se complejiza aún más. Para autopsiar un cadáver que puede tener coronavirus hay que disponer de una sala con ventilación adecuada, sitio para cambiarse y circulación doble, entre otros recaudos, que hoy no existe en el país.

\section{Reconvertir la "mala muerte"}

La mala muerte nos tocó la puerta y ya no supimos cómo actuar. Cuando se volvió imposible enfrentarla cara a cara, sólo hubo lugar para el vacío. Desde Chile, Panizo señaló que "en toda muerte hay un espacio de transición, donde el muerto de alguna manera permanece en la vida de los vivos algún tiempo". Arrebatada esa "instancia de convivencia y despedida", nos vimos imposibilitados de "visibilizar la muerte y el cuerpo, acompañarlo y tocarlo".

Extraordinaria, masiva y contaminante, la "mala muerte" del coronavirus nos descolocó. El concepto, explicó la investigadora a "Question", hace referencia al fallecimiento que "no es adecuado" y "está fuera de lugar".

Privados de las prácticas esenciales de despedida y separación, los deudos buscan "otros espacios de despedida". Alrededor del mundo comienza a implementarse velatorios online, altares virtuales y memoriales digitales. Tras ponderar estas nuevas forma de "asistir, acompañar y procesar" las pérdidas, hasta que "llegue el tiempo de hacerlo mejor", Panizo manifestó que "las malas muertes se pueden reconvertir".

De las sociedades dependerá cómo adecuarse a esta situación para transformar la "mala muerte" en algo que pueda "entrar en nuestro marco de entendimiento y darle un buen lugar", concluyó la antropóloga. 